\title{
A Comparative Analysis of JOURNEY Metaphors in Marketing English
}

\author{
Jinxiao Wang \\ School of English for International Business, \\ Guangdong University of Foreign Studies, China
}

\begin{abstract}
Metaphor is a powerful cognitive tool that can help to transmit marketing concept, and form effective marketing strategies. The conceptual metaphor of MARKETING IS JOURNEY has been viewed as a significant deep metaphor in the field of marketing all along. Based on five authoritative marketing textbooks and research articles of three high influencing factor journals in 2016, this paper builds a corpus of three million words. By virtue of previous studies, the author makes a check-list, and intends to explore the usage of JOURNEY metaphors in marketing English with the help of "Metaphor Identification Process (MIP)" (Steen at al. 2010) from the perspective of Conceptual Metaphor Theory. The results show that: (1) the productivity of CMTB is 64,209, which is much higher than that of CMJA, 32,184; (2) Themes of obstacles \& facilitators, directions of journey, uphill \& downhill, as well as fast \& slow progress of journey are widely employed in marketing English, with marketing research articles laying more focus on the theme of directions of journey than textbooks; (3) similarities and differences between them can be explained by the contextual factors of field, tenor, and mode. Further implications includes that it can help to appeal to further revision of established marketing textbooks, for that the most cutting-edge metaphorical expressions, e.g., "memory block", should be included in textbooks for better catching up with the latest development in the field of marketing.
\end{abstract}

Keywords: marketing; corpus; JOURNEY metaphors; Conceptual Metaphor Theory

\section{INTRODUCTION}

Conceptual metaphor theory holds that metaphor is not only a means of language rhetoric, but also a ubiquitous way of thinking. As the basis of human's cognition, thought, experience, language, and even behavior, metaphor is the main and basic way of human existence (Lakoff \& Johnson 1980). Metaphor consists of two domains: a source domain with relatively explicit structure and a target domain with relatively implicit structure. Metaphor is to map the schematic structure of the source domain to the target domain, so that we can construct and understand the target domain through the structure of the source domain (Lakoff 1993). For example, LIFE is a relatively abstract concept and its structure is vague, so it is often described by means of JOURNEY to form the conceptual metaphor of LIFE IS JOURNEY. Metaphorical mappings are not generated at random, but rooted in 
our physical experience (Lakoff \& Johnson 1999). Once a metaphorical mapping is established and accepted by most language users, it will in turn impose its mapping structure on our real life and be realized in various ways.

Textbooks are at the mature end of academy, while journal articles are at the frontier. A comparative study of their metaphors will help to provide reference for textbook writers so as to better serve teaching objectives. In recent years, marketing scholars and linguists have paid more and more attention to metaphors in the discipline of marketing, most of which are based on the introspection and intuition of scholars. Through corpus data, the research results of metaphors can be more convincing. By delving into corpora of marketing textbooks and journal articles, this paper explores the use of JOURNEY metaphors in these two genres and its underlying causes from the perspective of conceptual metaphor.

\section{Conceptual metaphor}

\section{LITERATURE REVIEW}

Metaphors are not only grounded in our physical and cultural experience, they also influence our experience and behaviors. Among them, conceptual metaphor is a natural part of human thought, and linguistic metaphor is a natural part of human language. Moreover, which metaphors we have and what they mean depend on the nature of our bodies, our interactions in the physical environment, and our social and cultural practices (Lakoff \& Johnson 1980). People construe many aspects of the social world using conceptual metaphors that apply the structure of concrete concepts to process information related to dissimilar, typically more abstract concepts.

\section{Metaphor in marketing}

Marketing is an abstract and complicated system, which in its nature requires numerous metaphors to help people interpret its concepts, and mechanisms, etc. Effective metaphor usage can lead to the goal of developing marketing programs to position products in consumers' minds, especially with respect to competitive products (Townsend, Montoya, \& Calantone 2011). However important metaphor is to the discipline of marketing, its discourse has only received limited attention, compared with the fertile research field of metaphor in economics. Most of them lay their focus on one conceptual metaphor, for instance, Durö \& Sandström (1988) analyzes the military metaphors in marketing via military strategies, Viot (2006) focus on the correlations between the metaphors of the personality of the brand and the scales of human personality and O'Malley, Patterson \& KellyHolmes (2008) explores the diachronic evolution of marketing as relationships framework.

There are two main research methods of marketing metaphor: theoretical research and empirical research. Among them, in theoretical research, researchers usually summarize previous literatures, and put forward their own views through induction and classification, combined with certain theories, such as Conceptual Metaphor Theory. Theoretical research can be divided into macroanalysis and micro-analysis, in which macro-analysis involves interdisciplinary research (Bremer, et al. 1997), while micro-analysis focuses on more detailed metaphorical phenomena (Cornelissen \& Harris 2001; Davies \& Chun 2003; Cornelissen 2003; Johnston \& Hausman 2006; Viot 2006; O’Malley 2008; Capelli \& Jolibert 2010). Empirical research includes observational method and experimental method (Jeong 2008; Chang, Wu, Lee \& Chu 2016), and observational method includes interview, case study (Hirschman 2007; Oakes 2009; Rentschler, Jogulu, Kershaw \& Osborne 2012; Brozovic, Ravald \& Nordin 2015), corpus method (Burcea 2010), metaphor induction (Sugai 2005; 
Zaltman \& Zaltman 2008) and discourse analysis (Miles 2014). Among them, Kitchen (2008) is probably the most complete collection so far, which encompasses the wide range of marketing metaphors of the globalization of markets, market segmentation, viral marketing, the product life cycle, etc.

In his book Marketing Metaphoria: What Deep Metaphors Reveal About the Minds of Consumers, Gerald Zaltman presents the solutions to overcome the depth deficits in understanding consumers' needs by delving into the universal drivers of human behavior, metaphors, vital to a firm's success. He outlines what he calls the seven giants, which are the most basic and most recurring deep metaphors in marketing: balance, transformation, journey, container, connection, resource, and control. According to Zaltman (2008), people's sense of the past, present, and future often combine to create the experience of a physical, social, or psychological journey.

Former researches have brought some light to our researches associated with conceptual metaphors in marketing. However, it seems that except for the work of Burcea (2010), little attention has been given to the field of academic marketing English, for instance marketing textbooks and research articles. Business English education in China has a history of more than 60 years. As one of the important components of Business English, marketing English textbooks have been developing rapidly in recent years, and various kinds of textbooks have emerged. In order to guarantee the quality of textbook compilation and teaching effect, textbook evaluation is an important and necessary means (Sun \& Wang 2013). This paper, basing on one of the seven deep metaphors raised by Zaltman, intends to compare the metaphorical patterns in marketing textbooks as well as research articles. It aims to delve into most frequently used conceptual metaphors in marketing, hoping to reveal the deviation between textbooks and frontier research articles. This paper can be seen as a tentative step towards the micro evaluation of currently widely applied marketing textbooks, and it hopes to suggest some heuristic significance for textbook designs.

\section{Research Questions}

\section{RESEARCH METHOD}

In light of the review and analysis of the previous studies, this paper poses three main research questions, which can be operationalized as followed: 1) what are the productivities of JOURNEY metaphors in marketing textbooks and journal articles? 2) what are the similarities and differences in the most concerned themes of marketing textbooks and journal articles? 3) what are the reasons underpinning these similarities and differences? What implications can be drawn from them?

\section{Corpora}

The corpora of this study are collected from five authoritative marketing textbooks, including Contemporary Marketing 13ed, Principles of Marketing 15ed, International Marketing 15ed, Marketing Management 14ed, and Marketing Research--An Applied Orientation 6ed, and three high influencing factor journals in 2016, including Journal of Marketing Research, Journal of Marketing, and Journal of Consumer Research. The two self-built corpora are Corpus of Marketing Textbooks (CMTB) of 1.67 million words, and Corpus of Marketing Research Articles (CMJA) of 1.84 million words, detail information of which is shown in Table 1. 
Table 1. Corpora information

\begin{tabular}{|c|c|c|}
\hline Corpus Name & CMTB & CMJA \\
\hline Title & $\begin{array}{c}\text { Contemporary Marketing } \\
\text { International Marketing } \\
\text { Marketing Management } \\
\text { Principles of Marketing } \\
\text { Marketing Research }\end{array}$ & $\begin{array}{c}\text { Journal of Consumer Research } \\
\text { Journal of Marketing Research } \\
\text { Journal of Marketing }\end{array}$ \\
\hline Year & $2007 、 2010 、 2012 、 2013$ & 2016 \\
\hline Tokens & $1,508,680$ & $1,750,690$ \\
\hline Quantity & 5 textbooks & 56 journal articles \\
\hline Target readers & Novices, beginners & Scholars, experts \\
\hline
\end{tabular}

\section{Procedure}

Anatol (2006) mentioned 7 approaches for the retrieval of metaphors from corpora, which are: 1) manual identification (Steen et al. 2010); 2) searching for source domains (Charteris-Black 2004; Deignan 2005); 3) searching for target domains; 4) searching for both domains; 5) searching for metaphor markers (Goatly 1997); 6) searching from semantic domains; 7) searching from mappings. This study uses the second method, in order to serve the goal of exploring JOURNEY metaphors in marketing English.

The procedure is divided into four steps. 1) form a check-list based on previous studies on JOURNEY metaphor; 2) add the two corpora into WordSmith Tools and retrieve each of the words in the check-list respectively; 3) manually read each concordance lines, and identify all the JOURNEY metaphors, borrowing the Metaphor Identification Method (MIP) of Pragglejaz Group (2007:3) and Steen et al. (2010). Use MacMillan English Dictionary for Advanced Learners (2003) as reference; 4) compute productivity for each corpus basing on Chartiris-Black (2004), and contrast the results of the two corpora for further analysis.

\section{Check-list}

Table 2 lists all together 80 source domain vocabularies extracted from Zaltman's book and other authoritative marketing related articles and books (sources are listed attached to each category), categorized on the basis of three of Zaltman's mentioned most often applied themes of journey, which are "known or unknown outcomes, obstacles and facilitators, and the ups and downs of journeys (Zaltman \& Zaltman 2008:87)". Two additional theme of "fast and slow", and "forward and backward" are added to categorize the deep metaphor of journey, basing on the check-list vocabularies collected. 
Wang, J. (2020) A Comparative Analysis of JOURNEY Metaphors in Marketing English. Advances in Social Sciences Research Journal, 7(5) 304-313.

\begin{tabular}{|c|c|c|}
\hline \multicolumn{3}{|c|}{ Table 2. Check-list } \\
\hline Themes & Check-list Vocabularies & Sources \\
\hline Known \& unknown & $\begin{array}{l}\text { Veer off, on track, detour, milestone, waypoint, } \\
\text { adventure, expedition, destination, end, beginning, } \\
\text { digress, stray, off track }\end{array}$ & $\begin{array}{c}\text { Zaltman \& Zaltman (2008), } \\
\text { Kövecses (2010) }\end{array}$ \\
\hline $\begin{array}{l}\text { Obstacles\& } \\
\text { facilitators }\end{array}$ & $\begin{array}{l}\text { obstacle, facilitator, stuck, bridge, hurdle, get over, } \\
\text { burdened, lurch, overcome, dead-end, on the rock, } \\
\text { founder, zigzag, roadblock, run aground, lost, barrier, } \\
\text { block, insurmountable, stumble, smooth, capsize, }\end{array}$ & $\begin{array}{l}\text { Goatly (1997), Deignan } \\
\text { (2001), Lakoff \& Johnsen } \\
\text { (2003), Zaltman \& Zaltman } \\
\text { (2008), Kövecses (2010), }\end{array}$ \\
\hline Uphill \& downhill & $\begin{array}{l}\text { uphill, downhill, climb, coast, rollercoaster, tidal wave, } \\
\text { plunge, soar, plummet, slump, dip, ups and downs, lift- } \\
\text { off, slope, slip, slide, tumble, }\end{array}$ & $\begin{array}{l}\text { Zaltman \& Zaltman (2008), } \\
\text { Kövecses (2010) }\end{array}$ \\
\hline Fast \& slow & $\begin{array}{l}\text { snail, turtle, tortoise, slow lane, fast lane, sprint, } \\
\text { traipse, gallop, head start, creep, jump the gun, quick } \\
\text { off the mark, superhighway, stagger, wander, } \\
\text { marathon, jog }\end{array}$ & $\begin{array}{l}\text { Goatly (1997), Deignan } \\
\text { (2001), Zaltman \& Zaltman } \\
\text { (2008), Kövecses (2010) }\end{array}$ \\
\hline $\begin{array}{l}\text { Forward \& } \\
\text { backward }\end{array}$ & $\begin{array}{l}\text { reverse, rewind, progress, onward, backward, forward, } \\
\text { turn back, headway, go along, crossroad, retreat }\end{array}$ & $\begin{array}{c}\text { Deignan (2001), Zaltman \& } \\
\text { Zaltman (2008), Kövecses } \\
\text { (2010) }\end{array}$ \\
\hline
\end{tabular}

\section{MIP}

The rational of MIP is simply that "[m]etaphorical meaning in usage is indirect meaning: it arises out of a contrast between the contextual meaning of a lexical unit and its more basic meaning, the latter being absent from the actual context but observable in others (Steen et al. 2010:6)". Thus the procedure of MIP, according to Pragglejaz Group (2007: 3) and Steen et al. (2010) contains: 1) read the entire text/discourse to establish a general understanding of the meaning; 2) determine the lexical units in the text/discourse; 3) for each lexical unit in the text, establish its meaning in context, and determine if it has a more basic contemporary meaning in other contexts than the one in the given context. If yes, decide whether the contextual meaning contrasts with the basic meaning but can be understood in comparison with it; 4) if yes, mark the lexical unit as metaphorical.

\section{RESULTS \& ANALYSIS}

\section{Productivity of JOURNEY metaphors used in CMTB and CMJA}

According to Charteris-Black (2004), the productivity of metaphors can be measured by resonance. Resonance is "an indication of the extent to which metaphor source domains are found in a particular corpus", the statistical measure of which is that it is the sum of the tokens multiplied by the sum of the types of the metaphors that are from the same source domain. (Charteris-Black 2004:89)". As shown in Table 3, the productivity of CMTB is 64,209 , and that of CMJA is 32,184 .

Table 3. Productivities of CMTB \&CMJA

\begin{tabular}{|c|c|c|c|}
\hline Corpora & Types & Tokens & Resonance \\
\hline CMTB & 51 & 1,259 & 64,209 \\
\hline CMJA & 36 & 894 & 32,184 \\
\hline
\end{tabular}

To explore the reasons of such significant variances between the two corpora, the type of CMTB is 51, which far exceeds 36 of CMJA. Specifically, types of "on track", "expedition", "roadblock", "stumble", "insurmountable", etc. are absent from CMJA, and the tokens of "soar", "forward", "obstacle”, "beginning”, "barrier”, etc. in CMTB are much higher than those in CMJA. 


\section{Comparative Analysis of the Themes used in CMTB and CMJA}

Table 4. Productivities of each themes

\begin{tabular}{|c|c|c|c|c|c|c|}
\hline & \multicolumn{2}{|c|}{ Types } & \multicolumn{2}{c|}{ Tokens } & \multicolumn{2}{c|}{ Resonance } \\
\hline & CMTB & CMJA & CMTB & CMJA & CMTB & CMJA \\
\hline Known \& unknown & 8 & 7 & 417 & 179 & 3,336 & 1,253 \\
\hline Obstacles\& facilitators & 15 & 12 & 496 & 265 & 7,440 & 3,180 \\
\hline Uphill \& downhill & 15 & 8 & 137 & 15 & 2,055 & 120 \\
\hline Fast \& slow & 5 & 4 & 7 & 9 & 35 & 36 \\
\hline Forward \& backward & 8 & 5 & 202 & 426 & 1,616 & 2,130 \\
\hline
\end{tabular}

As can be drawn from Table 4, in the themes of "obstacles and facilitators", "uphill and downhill", the productivities of CMTB are higher than that of CMJA; in the theme of "fast and slow", the productivities of both the two corpora are close, and far lower than those in other themes. What is interesting is that in the theme of "forward and backward", the productivity of CMTB is 1,616, which is lower than that in CMJA, 2,130. A closer examination of the corpora may help to explain the results above, which is displayed in Table 5, a ranking of the distribution of the Top 5 check-list vocabularies in each theme.

Table 5. Distribution of Top 5 check-list words

\begin{tabular}{|c|c|c|c|}
\hline Themes & Check-list words & CMTB & CMJA \\
\hline \multirow{5}{*}{ Known \& unknown } & end & 292 & 149 \\
\hline & beginning & 101 & 16 \\
\hline & milestone & 7 & 3 \\
\hline & adventure & 5 & 3 \\
\hline & destination & 5 & 1 \\
\hline \multirow{5}{*}{ Obstacles \& facilitators } & barrier & 220 & 25 \\
\hline & overcome & 115 & 62 \\
\hline & block & 37 & 74 \\
\hline & obstacle & 31 & 8 \\
\hline & smooth & 26 & 8 \\
\hline \multirow{5}{*}{ Uphill \& downhill } & soar & 39 & 1 \\
\hline & climb & 19 & 1 \\
\hline & slump & 16 & 2 \\
\hline & plummet & 12 & 3 \\
\hline & plunge & 11 & 3 \\
\hline \multirow{5}{*}{ Fast \& slow } & snail & 2 & 0 \\
\hline & head start & 2 & 6 \\
\hline & gallop & 1 & 0 \\
\hline & superhighway & 1 & 0 \\
\hline & marathon & 1 & 0 \\
\hline \multirow{5}{*}{ forward \& backward } & reverse & 50 & 162 \\
\hline & progress & 85 & 246 \\
\hline & forward & 46 & 1 \\
\hline & backward & 16 & 16 \\
\hline & retreat & 2 & 0 \\
\hline
\end{tabular}


Wang, J. (2020) A Comparative Analysis of JOURNEY Metaphors in Marketing English. Advances in Social Sciences Research Journal, 7(5) 304-313.

\section{Known and unknown journeys}

As can be seen from Table 5, the tokens of "end" and "beginning" contribute most to the high productivity of CMJA in the theme of "known and unknown journeys. Expressions of "high-end", "end user" appears in both corpora (Example 1), while the "beginning" of marketing activities is seldom seen in CMJA.

1) Sometimes the market will divide into low- and high-end segments, and market shares of firms in the middle steadily erode. (CMTB: Marketing Management)

\section{Obstacles and facilitators}

There might be stumbling or stepping stones in a journey, making it more difficult or easier. In the theme of "obstacles and facilitators", metaphorical expressions of "barrier" and "overcome" are relatively higher. For instance, "trade barrier", "tariff barrier", "overcome economic and social imbalances" are usual occurrences in marketing textbooks. However, metaphorical indexes of "block" seem to be more frequent in CMJA than that in CMTB. "Memory blocking", and "blocking effect" are primary cause for this result.

2) Trade routes represent the attempts of countries to overcome economic and social imbalances created in part by the influence of geography. (CMTB: International Marketing)

3) Memory blocking refers to such negative effects of recall, whereby the act of retrieving some information blocks other information. (CMJA: When Remembering Disrupts Knowing Blocking Implicit Price Memory)

\section{Uphill and downhill}

In a journey, "uphill journeys typically feature difficulties and struggle and can be emotionally daunting. Downhill journeys can have both positive and negative connotations (Zaltman \& Zaltman 2008). The metaphors of uphill and downhill journey in CMTB and CMJA are widely divergent. It can be observed from Table 3 that apart from several close behaving tokens, most check-list words are far more recurrent in CMTB than in CMJA. Patterns like "sales 'plunge, slump'”, and "revenue 'soar'” are uncommon in CMJA.

4) As oil prices soar, companies search for practical means to harness solar, nuclear, wind, and other alternative energies. (CMTB: Marketing Management)

5) As a result, the company's sales revenues climbed and so did its margins. (CMTB: Marketing Management)

\section{Fast and slow}

In the theme of "fast and slow", the metaphorical expressions in both the two corpora are rare, with the highest frequency of 6 in CMJA. This is partly due to the limited words in the check-list, which is because the numbers of items of different source domains are naturally different considering the arbitrariness of language itself. In CMTB the most frequent metaphors are "snail" and "head start". 
6) For instance, it is estimated that the volume of e-mail today exceeds regular mail (sometimes jokingly called snail mail ) by something like ten to one. (CMTB: Contemporary Marketing)

\section{Forward and backward}

Travelers encounter many crossroads in their journey, the choices of which concerns whether the ways to their destinations are smooth or rough. In marketing, different "directions" exists as well, e.g. when executing buying behaviors, consumers "skip" or "reverse" some "stages" or "steps" in their way to the final buying. In this theme, due to the effect of "reverse" and "progress", which accounts for $18.12 \%$ and $27.52 \%$, CMJA tends to behave more productively than CMTB.

8) Studies could also investigate the reverse effect, from physical activity to food consumption. (CMJA: The Effect of Fitness Branding on Restrained Eaters' Food Consumption and Postconsumption Physical Activity)

9) A series of lab and field studies indicate that the number, the nature, and the relative salience of progress markers along a path to the goal affect perceptions of goal progress and goal pursuit. (CMJA: Altering Speed of Locomotion)

\section{DISCUSSION}

According to the register theory of Halliday, contextual factors are consisted of field, tenor, and mode. The modes of marketing textbooks and research articles are both written forms, with the latter more rigid. Both marketing textbooks and journal articles focus on marketing topics, with the two of them at the different ends of academy. Textbook discourses are more mature and widely accepted marketing theories. However, in journal articles, cutting-edge discourses which need to be tested in practice are more recurrent, which explains the new terminologies, such as "reverse causality", and "memory blocking", etc.

The tenors of both marketing textbooks and journal articles are similar, which are both distant. However, there are slight differences in that textbooks are for beginners and novices who aim to learn the basic knowledge about this discipline. On the contrary, journal articles are for experts and scholars. The differences of the target audiences explain why there are more vivid expressions in CMTB than in CMJA: the authors try to use their readers' familiar domains to align them and form a close author-reader relationship. The differences of these three contextual factors result in the differences of metaphor choices in marketing textbooks and journal articles.

\section{CONCLUSION}

This paper takes five authoritative marketing textbooks and three high influencing factor marketing journal articles as corpora, explores and contrasts the usages of the JOURNEY metaphors in them. The results show that 1 ) the productivity of CMTB is 64,209, which is almost twice than that of CMJA, 32,$184 ; 2$ ) marketing textbooks concern more about the themes of "obstacles and facilitators", and "uphill and downhill", while journal articles lay more focus on the theme of "forward and backward"; 3) similarities and differences between them can be explained by the contextual factors of field, tenor, and mode. Further implications can also be drawn from this paper: as mentioned by Zaltman et al. (1982: 170), "there are probably few areas of inquiry in the social sciences that rely on metaphor to the degree marketing does". For a discipline as abstract as marketing, metaphor 
plays a vital role in helping learners to understand the theories, terminologies, and models in this field. The study of deep metaphors in marketing can thus be of great help to those who aim to grasp the gist of this discipline, and metaphor, in this sense, can help improve the effectiveness of learning, for its interactive nature of two seemingly deviant semantic domains. Studies of this kind can also help to appeal to further revision of established marketing textbooks, for that the most cutting-edge metaphorical expressions, like the aforementioned "memory block", should be included in textbooks for better catching up with the latest development in the field of marketing.

Despite some findings of this paper, it uses a 80-word check-list as a starting point, which limits the exhaustiveness of JOUNREY metaphors in marketing textbooks as well as journal articles. What's more, only the source domain of JOURNEY is explored in this paper, which can bias the results of comparison as well. Future studies can include more check-list vocabularies in previous studies and more source domains, in order to get a more holistic view of how the leading deep metaphors are distributed in marketing English.

\section{References}

Bremer, K., \& Lee, M. (1997). Metaphors in Marketing: Review and Implications for Marketers. Advances in Consumer Research.

Brozovic, D., Ravald, A., \& Nordin, F. (2015). Making sense of service dynamics: the honeybee metaphor. Journal of Services Marketing, 29(6/7), 634-644.

Burcea, R. (2011). Metaphorical Conceptualizations of Marketing. Annals of Spiru Haret University Economic, 1(3), 153-160.

Capelli, S., \& Jolibert, A. (2010). Metaphor’s validity in marketing research. Psychology \& Marketing, 26(12), 10791090.

Chang, C. T., Wu, Y. C., Lee, Y. K., \& Chu, X. Y. (2017). Right metaphor, right place: choosing a visual metaphor based on product type and consumer differences. International Journal of Advertising, 37(3), 1-28.

Charteris-black, J. (2004). Corpus Approaches to Critical Metaphor Analysis: Palgrave Macmillan.

Cornelissen, J., \& Harris, P. (2001). The Corporate Identity Metaphor: Perspectives, Problems And Prospects. Journal of Marketing Management, 17(1-2), 49-71.

Cornelissen, J. P. (2003). Metaphor as a method in the domain of marketing. Psychology \& Marketing, 20(3), 209-225.

Davies, G., \& Chun, R. (2003). The Use of Metaphor in the Exploration of the Brand Concept. Journal of Marketing Management, 19(1-2), 45-71.

Deignan, A. (2005). Metaphor and Corpus Linguistics.

Durö, R., \& Sandström, B. (1998). Stratégies guerrières en marketing. Paris: Les Editions d' Organisation.

Goatly, A. (1997). The language of metaphors. London: Routledge.

Group, P. (2007). MIP: A Method for Identifying Metaphorically Used Words in Discourse. Metaphor \& Symbol, 22(1), 1-39.

Hirschman, E. C. (2007). Metaphor in the marketplace. Marketing Theory, 7(3), 227-248.

Jeong, S. H. (2008). Visual Metaphor in Advertising: Is the Persuasive Effect Attributable to Visual Argumentation or Metaphorical Rhetoric? Journal of Marketing Communications, 14(1), 59-73.

Johnston, W. J., \& Hausman, A. (2006). Expanding the marriage metaphor in understanding long-term business relationships. Journal of Business \& Industrial Marketing, volume 21(7), 446-452.

Kitchen, P. J. (2008). Marketing: Metaphors and Metamorphosis. 
Kövecses, Z. (2010). Metaphor: A Practical Introduction. OUP USA.

Lakoff, G. (1993). The contemporary theory of metaphor. Metaphor \& Thought, 10(4), 374-379.

Lakoff, G., \& Johnson, M. (1980). Metaphors We Live By.

Lakoff, G., \& Johnson, M. (1999). Philosophy in the Flesh: The Embodied Mind and its Challenge to Western Thought. New York: Basic Books.

Miles, C. (2014). The rhetoric of managed contagion--Metaphor and agency in the discourse of viral marketing. Marketing Theory, 14(1), 3-18.

Oakes, S. (2009). Freedom and constraint in the empowerment as jazz metaphor. Marketing Theory, 9(4), 463-485.

O'Malley, L., Patterson, M., \& Kelly-Holmes, H. (2008). Death of a metaphor: reviewing the marketing as relationships' frame. Marketing Theory, 8(2), 167-187.

Rentschler, R., Jogulu, U., Kershaw, A., \& Osborne, A. (2012). Extending the theory of metaphor in marketing: The case of the art gallery. Journal of Marketing Management, 28(11-12), 1464-1485.

Steen, G. J., et al. (2010). A Method for Linguistic Metaphor Identification. John Benjamins Pub Co.

Stefanowitsch, A. (2006). Corpus-based Approaches to Metaphors and Metonymys: Mouton de Gruyter.

Sugai, P. (2005). Mapping the mind of the mobile consumer across borders: An application of the Zaltman metaphor elicitation technique. International Marketing Review, 41(22), 641-657.

Sun, Y., \& Wang, L. (2013). An Evaluation of Business English: An Integrated Course Basing on Metaphor Use. Foreign Language World(4), 48-54.

Townsend, J. D., Montoya, M. M., \& Calantone, R. J. (2011). Form and function: A matter of perspective. Journal of Product Innovation Management, 28, 374-377.

Viot. (2006). “Personnalité de la marque: la métaphore justifie-t-elle la transposition d'échelles de personnalité humaine?", (paper presented at the 5th International Congress ESCP-EAP “Marketing Trends”, Venice, January 20-21, 2006).

Zaltman, G., LeMasters, K., \& Heffring, M. (1982). Theory Construction in Marketing: Some Thoughts on Thinking: John Wiley and Sons.

Zaltman, G., \& Zaltman, L. H. (2008). Marketing metaphoria: Harvard Business School Press. 